\title{
Training Self-Regulated Learning in the Classroom: Development and Evaluation of Learning Materials to Train Self-Regulated Learning during Regular Mathematics Lessons at Primary School
}

\author{
Manuela Leidinger and Franziska Perels \\ Department of Educational Research, Saarland University, 66123 Saarbrücken, Germany \\ Correspondence should be addressed to Manuela Leidinger, manuela.leidinger@mx.uni-saarland.de
}

Received 1 June 2012; Revised 27 July 2012; Accepted 13 November 2012

Academic Editor: Susanne Narciss

Copyright ( $) 2012$ M. Leidinger and F. Perels. This is an open access article distributed under the Creative Commons Attribution License, which permits unrestricted use, distribution, and reproduction in any medium, provided the original work is properly cited.

\begin{abstract}
The aim of the intervention based on the self-regulation theory by Zimmerman (2000) was to promote a powerful learning environment for supporting self-regulated learning by using learning materials. In the study, primary school teachers were asked to implement specific learning materials into their regular mathematics lessons in grade four. These learning materials focused on particular (meta)cognitive and motivational components of self-regulated learning and were subdivided into six units, with which the students of the experimental group were asked to deal with on a weekly basis. The evaluation was based on a quasiexperimental pre-/postcontrol-group design combined with a time series design. Altogether, 135 fourth graders participated in the study. The intervention was evaluated by a self-regulated learning questionnaire, mathematics test, and process data gathered through structured learning diaries for a period of six weeks. The results revealed that students with the self-regulated learning training maintained their level of self-reported self-regulated learning activities from pre- to posttest, whereas a significant decline was observed for the control students. Regarding students' mathematical achievement, a slightly greater improvement was found for the students with self-regulated learning training.
\end{abstract}

\section{Introduction}

According to Boekaerts et al. [1], the concept of selfregulation is used in a variety of psychological fields (see also [2]). In research on educational settings, self-regulated learning [3] is classified as an important factor for effective (school-based) learning and academic achievement (e.g., [4-6]).

Regarding theories and models of self-regulation, there are different approaches to describe the construct. Some models regard self-regulation as consisting of different layers (e.g., [7]), while other models emphasize the procedural character of self-regulation and describe different phases (e.g., $[8-10])$. In our study, we refer to the self-regulation model developed by Zimmerman [8], who defines selfregulation as a cyclical process that "refers to self-generated thoughts, feelings, and actions that are planned and cyclically adapted to the attainment of personal goals" (page 15). The model distinguishes between three learning phases: the forethought or planning phase, the performance or volitional control phase, and the self-reflection phase. For each of these phases, two components are uniquely characterized which are again represented by specific processes.

As components of the forethought phase, both the analysis of the given task (task analysis) and self-motivation beliefs are relevant variables in the beginning of the learning process. Task analysis includes processes of goal setting and strategic planning. According to Locke and Latham [11], goal setting has been defined as a decision upon specific outcomes of learning or performance. Highly selfregulated students organize their goal systems hierarchically and tend to set process goals in order to achieve more 
distal outcome goals [8]. Furthermore, strategic planning is a process relevant to the forethought phase-and closely related to goal setting-because after selecting a specific goal, students engage in planning how to reach it $[9$, 12]. Indeed, these processes are quite useless if students are not motivated or cannot motivate themselves to use corresponding strategies. Therefore, self-motivation beliefs, such as self-efficacy, outcome expectations, intrinsic value, and goal orientation, are relevant motivational variables of the forethought phase and they affect direction, intensity, and persistence of students' learning behavior [13, 14]. Self-efficacy refers to "personal beliefs about having the means to learn or perform effectively" [15, page 17], whereas outcome expectations refer to the judgments of the consequences that behavior will produce [16]. In line with Deci and Ryan [17], intrinsic value is defined "as the doing of an activity for its inherent satisfaction rather than for some separate consequences" (page 56). Regarding goal orientation, there is a first distinction between a mastery goal construct and performance goal construct (e.g., [18]): whereas mastery goals (also called mastery orientation) are focused on learning and self-improvement, performance goals (also called performance orientation) represent a more general concern with demonstrating ability and trying to do better than (or to not appear worse than) others $[19,20]$. There is a distinction between two different types of performance goals: performance-approach goals and performanceavoidance goals [18]. Students can be motivated to try to outperform others in order to demonstrate their competence (performance-approach) or to avoid failure in order to avoid looking incompetent (performance-avoidance). With respect to self-regulated learning theory, a positive influence of mastery goals on the different components of self-regulated learning was found [10]. In addition, these motivational variables are important components of selfregulated learning as they initiate the learning process and affect students' performance [14].

In the next phase- the performance or volitional control phase-self-regulated learning is determined by processes of self-control and self-observation. In this regard, selfcontrol strategies-or volitional strategies-are necessary when disturbances occur while performing a task [21, 22]. In his model, Zimmerman [8] differentiated between selfinstruction, task strategies, imagery, and attention focusing as important strategies of self-control. Corno [23] emphasized that a flexible use of volitional strategies assists selfregulated learning because it enables students to shield their goal-related behavior from distractions. In the framework of our study, we concentrated on attention focusing as an effective self-control strategy in avoiding distractions and speculations of irrelevant matters [24].

Another important component of the performance phase concerns the ability of self-observation, which is described as the systematic observation and documentation of thoughts, feelings, and actions regarding goal attainment [25]. Regarding self-regulated learning, students cannot adequately engage in self-regulatory behavior without self-observation because they are only able to modify their behavior if they are attentive to relevant aspects of it [26]. As for the processes of self-observation, Zimmerman [8] adduced the processes of self-recording and self-experimentation. Self-recording has the advantage of retaining personal information at the point when it occurs and includes the possibility of altering or modifying the behavior. Self-experimentation offers the possibility of systematically varying different aspects of behavior. As a common self-recording technique, Zimmerman [8] argued for diaries to support self-observation processes because of the reactivity effect [27].

Subsequent to the performance phase, the completion of a task is the initial point of the self-reflection phase. This phase is characterized by the components of selfjudgment and self-reaction. Zimmerman [8] describes selfjudgment as consisting of two processes: self-evaluation and causal attributions, which includes the comparison of one's behavior with one's goals [28]. Students evaluate their learning results and draw conclusions concerning further learning behavior. In this context, there are different types of criteria to evaluate one's performance. In line with Zimmerman [8], we distinguished between normative criteria and self-criteria. In this context, self-criteria are regarded as being more effective for self-regulated learning [29] because they involve the comparison of current performance with earlier levels of performance and allow judgments about the learning progress. Self-evaluative judgments are related to causal attributions. Students attribute their behavior by considering the results. There is evidence that in cases of poor performance, attributions to insufficient effort or a poor task strategy can be beneficial to motivational aspects; in cases of successful performance, attributions to one's ability are beneficial to motivation [30,31]. The comparisons of results to goals, as well as causal attributions, are linked to the students' affect or self-reactions. In this context, Zimmerman [8] described perceptions of satisfaction or dissatisfaction (called self-satisfaction) and distinguished between adaptive or defensive interferences that modify a person's self-regulatory approach during subsequent efforts to learn or perform. Thereby, the feedback resulting from current performance influences prospective performance. Zimmerman [8] designated this procedural nature of selfregulation as a feedback loop. The theoretical model is depicted in Figure 1.

As self-regulated learning has become a key construct in education in recent years because of its importance in influencing learning and achievement in school and beyond [33], there are many studies on enhancing students' self-regulatory abilities by training them either during or after their regular classes (e.g., [34-36]). Leopold et al. [37] fostered text understanding by the intervention of text highlighting and self-regulation strategies. Souvignier and Mokhlesgerami [38] focused on the enhancement of cognitive, motivational, and metacognitive aspects of selfregulated learning with respect to reading comprehension. Regarding science lessons, Labuhn et al. [39] trained seventh graders in cooperation with teachers. The target groups of these studies were students at the secondary school level (ranging from fifth to eleventh grade). As the development of self-regulation begins in early childhood $[40,41]$, and in line with the results of a meta-analysis by Dignath and 


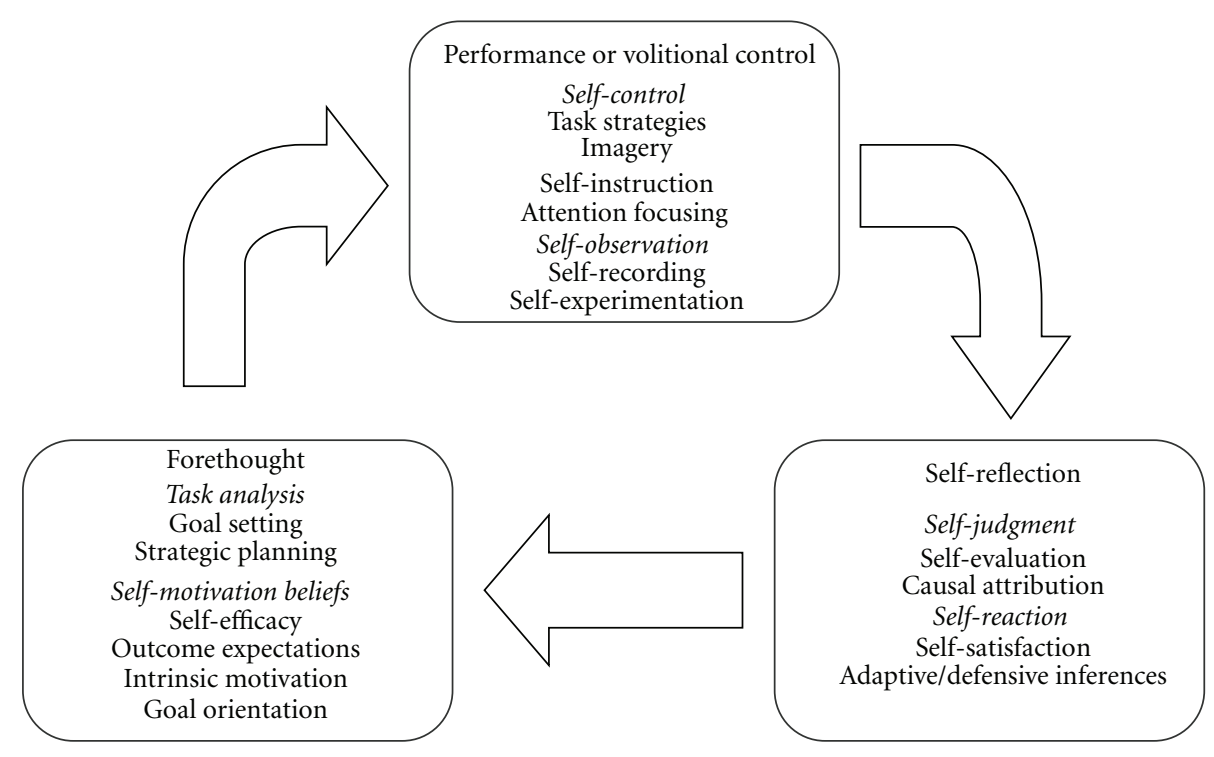

Figure 1: Phases and processes of self-regulation [32].

Büttner [42], interventions have been developed to foster self-regulated learning of students in primary school [43, 44] or even kindergarten [45]. Dignath et al. [46] pointed out that improving the self-regulated learning of primary school students has positive effects on learning outcomes, strategy use, and motivation (see also [47]). Otto [43] trained primary school students, as well as their teachers and parents, and was able to compare direct and indirect effects of selfregulation training. Rozendaal et al. [48] followed a similar approach. In the framework of their study, they trained significant reference persons (teachers) on how to improve students' self-regulated learning abilities [49].

The abovementioned studies represent different approaches to enhance self-regulated learning by training either students themselves or other relevant persons, such as teachers or parents. Thereby, self-regulated learning was combined with different academic subjects such as reading comprehension, text understanding or mathematical modelling, and problem-solving. This approach is in line with the results of a meta-analysis conducted by Hattie et al. [50], which pointed out that the direct and isolated instruction of self-regulated learning strategies had turned out to be less effective regarding its transferability on students' learning behavior. Instead, the authors argued that direct instruction of strategies ought to be linked to factual content in order to apply these strategies in a natural setting. With regard to mathematical learning, De Corte et al. [51] argued that "self-regulation constitutes a major characteristic of productive mathematics learning" because the main goal of learning and teaching mathematics concerns "the ability to apply meaningfully learned knowledge and skills flexibly and creatively in a variety of contexts and situations" (page 155). There are a few studies (e.g., $[47,49]$ ) that combine the instruction of mathematical problem-solving strategies with multidisciplinary self-regulated learning strategies. The presented study was designed with regard to the approach of De Corte et al. [52], who promoted the conception of the powerful learning environment, which fosters the application of self-regulatory learning strategies. Therefore, the teachers received teaching materials that included instructions to train their students in their natural learning environment at school. Following the processual character of Zimmerman's model [8], these materials focused on particular strategies of each of the three phases. In detail, the forethought phase was represented by strategies of goal setting, strategic planning, and intrinsic value. With respect to the following phases, the learning materials focused on attention focusing as a strategy of the performance or volitional control phase and on causal attribution as a strategy of the self-reflection phase. In order to enhance their transferability, the learning materials were related to the current mathematics curriculum. As self-regulated learning strategies are transferable to different situations and areas [53], students should be thus enabled to use these strategies in different contexts.

\section{Hypotheses}

As the intervention was designed in order to improve selfregulated learning strategies of fourth grade students, the purpose of the study dealt with the influence of self-regulated learning interventions on students' self-regulated learning. In addition, an effect was expected on students' mathematics achievement because the intervention was conducted with respect to mathematical contents and conducted during regular mathematics lessons. In the framework of the study, a training to improve self-regulated learning was developed and implemented into regular mathematics lessons for a period of six weeks. In this process, the teachers received learning materials and instructions on how to train their students. It was expected that training particular self-regulatory processes could have an effect on students' self-regulated 
learning. Longitudinally, there should be an increase in selfregulated learning strategies in the trained group compared to the control group. In detail, the variables goal setting, strategic planning, intrinsic value, attention focusing, and causal attribution, as well as self-regulated learning, should be enhanced in the experimental group. As the training was linked to the contents of the mathematics curriculum, an effect of the intervention on the mathematical achievement of the trained students was expected, too. There should be found a stronger increase in mathematics achievement in the trained group compared to the control group. As the training effects were expected to be stable, there should be no significant changes of variables between posttest and followup measurement in the experimental group.

Beyond the pre/posttests, the students of the experimental group were also asked to complete a structured diary task addressing their self-regulated learning. Therefore, process data could be analyzed by means of interrupted time series analyses. With regard to the trained variables goal setting, strategic planning, intrinsic value, attention focusing, and causal attribution, intervention effects were assumed. In addition, it was expected that variables, which were not part of the training but dealt with within the diary, improved over the intervention period. This should be the case for the variables self-efficacy, self-recording, and self-evaluation as well as for self-regulated learning in general.

\section{Method}

3.1. Participants. The study was conducted in seven German primary schools with altogether 135 fourth graders. The participation was voluntary and the students' legal guardians were asked for their consent. In the experimental group (EG), 63 students took part, whereas 72 students were assigned to the control group. The mean age of the participants was $9.26(\mathrm{SD}=.56)$, and $50.40 \%$ were female. There were no significant differences between the experimental and control group concerning students' mathematics marks $(t=-1.56$, $P=.12$ ), and the mathematics marks on their report card ( $t=-0.44, P=.66)$. The students of the experimental group were involved in training carried out by their teachers. The control group did not receive any training.

3.2. Design. The study was evaluated by a time series design combined with a longitudinal design, including pretesting and posttesting of an experimental group (EG) and a control group (CG). The experimental group was trained in selfregulated learning and each student was asked to fill out a learning diary for the duration of the training. The control group was a group receiving neither training nor diaries.

3.3. Intervention. Based on the study of Perels et al. [49], learning materials to foster self-regulated learning strategies were developed with respect to fourth grade students' learning abilities. The learning materials were addressed to (meta)cognitive strategies, such as goal setting, and strategic planning, as well as to volitional/motivational strategies, such as intrinsic value, attention focusing, and causal attribution. On the one hand, these strategies were selected with respect
TABLE 1: Overview of the contents of the different units.

\begin{tabular}{lc}
\hline Session/unit & Content \\
\hline 1st unit & Introduction of Kalli Klug/learning diary \\
2nd unit & Goal setting \\
3rd unit & Strategic planning \\
4 th unit & Intrinsic value \\
5 th unit & Attention focusing \\
6th unit & Causal attribution \\
\hline
\end{tabular}

to the (meta)cognitive abilities of primary school students because it had to be taken into account that students of this age have a growing (metacognitive) awareness of their own thinking processes and have the opportunity to control them [40]. As Bronson pointed out, primary school students "can learn to consciously set goals, select appropriate strategies to reach the goals, monitor progress and revise their strategies when necessary, and control attention and motivation until a goal is reached" [40, page 213]. On the other hand, the learning materials focused on the abovementioned strategies in order to represent the different phases of Zimmerman's self-regulation model [8]. Therefore, goal setting, strategic planning, and intrinsic value were selected according to the forethought phase, while the strategy of attention focusing represented the performance and volitional control phase. As a strategy belonging to the self-reflection phase, causal attribution was selected.

The learning materials focused on the abovementioned strategies and were differentiated between six units. Each of these units—excluding the first—referred to one particular self-regulated learning strategy. In order to impart these selfregulatory contents to the students in a playful and childoriented manner, a fictitious character named Kalli Klug was developed with which the students could identify themselves, and which guided them through the different units. The first unit aimed to introduce the fictitious character to the students; therefore, a one-page profile of Kalli Klug was handed out to the students. The students learned that the character was an endearing bear of the age of nine, which had learned several strategies that helped him to improve his learning behavior and who wanted to relay this information to the students. In this context, a learning diary was introduced as one method to optimize learning behavior. The contents of units 2 and 3 were related to cognitive and metacognitive strategies. In detail, the third unit of the learning materials includes cognitive and metacognitive strategies because the students were asked to apply particular cognitive learning strategies such as organizing as well as metacognitive strategies like comprehension monitoring. The units 4 and 6 dealt with motivational strategies, such as self-motivation and favorable attributional styles. The fifth unit focused on volitional strategies, such as attention focusing. Table 1 gives an overview of the contents of the units.

Every unit was designed for the duration of one lesson (45 minutes). The teachers received the learning materials in the form of units according to the number of students in the classroom and the instruction plans on how to impart the 
TABLE 2: Overview of the scales of the self-regulated learning questionnaire regarding the sources, authors, and changes.

\begin{tabular}{lllr}
\hline Scale & Changes & Source & \multicolumn{1}{c}{ Author } \\
\hline Goal setting & Simplified formulation of the items & SELVES & Otto [43], Schmidt [54] \\
Strategic planning & $\begin{array}{l}\text { Simplified formulation of the items } \\
\text { One additional item }\end{array}$ & SELVES & Otto [43] \\
Intrinsic value & Simplified formulation of the items & & Otto [43], Gürtler [55], \\
& Sekrun et al. [56] \\
Attention focusing & Three additional items & SELVES & Otto [43] \\
Self-recording & Simplified formulation of the items & SELVES & Otto [43] \\
Self-evaluation & Simplified formulation of the items & SELVES & Otto [43] \\
Causal attribution & Simplified formulation of the items & & Bruder [57] \\
\hline
\end{tabular}

TABLE 3: Reliabilities of the self-regulated learning questionnaire.

\begin{tabular}{|c|c|c|c|c|c|}
\hline \multirow{2}{*}{ Phase } & \multirow{2}{*}{ Scale } & \multirow{2}{*}{$N$} & \multicolumn{3}{|c|}{ Cronbach's alpha } \\
\hline & & & Pretest & Posttest & Followup \\
\hline Forethought phase & Goal setting & 4 & .54 & .61 & .74 \\
\hline \multirow{2}{*}{$\begin{array}{l}\text { (e.g. "Before I start with a mathematics task, I plan } \\
\text { how to begin") }\end{array}$} & Strategic planning & 3 & .58 & .71 & .65 \\
\hline & Intrinsic value & 6 & .80 & .85 & .79 \\
\hline Performance or volitional control & Attention focusing & 6 & .76 & .79 & .74 \\
\hline $\begin{array}{l}\text { (e.g. "When doing a complex mathematics task, I } \\
\text { control whether my proceeding is reasonable") }\end{array}$ & Self-recording & 3 & .65 & .76 & .81 \\
\hline Self-reflection & Self-evaluation & 4 & .56 & .80 & .71 \\
\hline $\begin{array}{l}\text { (e.g. "If I failed a mathematics task, I reflect on what } \\
\text { to change next time") }\end{array}$ & Causal attribution & 5 & .67 & .65 & .58 \\
\hline Overall scale & Self-regulated learning & 31 & .90 & .92 & .88 \\
\hline
\end{tabular}

$N$ : number of items; followup: follow-up measurement after 12 months.

contents. Additionally, they received supporting documents which explained the theoretical background of the units. Every unit followed the same procedure: each began with a short repetition of the preceding unit. Then, the teachers demonstrated a new problem with which the character had been confronted (e.g., how to deal with distractions that restrict one from learning). Following this, the students had to think about this problem and find strategies to solve the problem. Alternatively, they learned the strategies which the character used in order to solve the problem by itself. In addition, the students had to transfer these strategies to their own learning behavior. The units finished with a task that had to be done for homework.

The teachers were asked to work on these learning materials together with their students during their regular mathematics lessons. In order to support the implementation of the contents, the teachers received instructions with recommendations for proceeding. It was the teachers' task to transfer these interdisciplinary strategies to the mathematical contents of their lessons. For example, the second unit focused on goal setting. The students learned how to set goals and were prompted to set their personal goals for their mathematics learning for the following week. Therefore, it can be said that the teachers were actively and personally involved in the implementation of the training.
The learning materials were made available to the teachers a week before the official start of the training. As the students had to work on one unit per week, there was enough time for the teachers to familiarize themselves with the learning materials. Further support was available in the form of a mentor, available at a teacher's discretion [58].

\subsection{Instruments}

3.4.1. Self-Regulated Learning Questionnaire. Within the framework of the study, a questionnaire was used to measure fourth grade students' self-regulated learning. A first version of this questionnaire was tested and revised in a pilot survey with a parallel student target group $(N=58)$. The students filled out the questionnaire a week before and after the intervention, as well as after a period of twelve months (follow-up measurement). The responses were coded on a scale with scores ranging from 1 to 4 (1: I disagree, 2: I somewhat disagree, 3: I somewhat agree, and 4: I agree). Some of the items have been taken from established instruments $[43,59-61]$, and, if necessary, selected scales were newly developed (for details, see Table 2). Reliabilities (Cronbach's alpha) were assessed for all scales (Table 3 ).

The questionnaire was applied during regular classes and instructed by qualified experimenters in a standardized 
TABLE 4: Split-half reliabilities of diary scales, evaluated with the odd-even method.

\begin{tabular}{lc}
\hline Scale & $r_{\text {odd-even }}$ \\
\hline Forethought phase & .92 \\
Goal setting & .69 \\
Strategic planning & .95 \\
Intrinsic value & .96 \\
Self-efficacy & \\
Volitional control phase & .90 \\
Attention focusing & .93 \\
Self-recording & \\
Self-reflection phase & .95 \\
Self-evaluation & .83 \\
Causal attribution & \\
\hline
\end{tabular}

All items: $P<.001 ; N=63$.

way. On the one hand, the questionnaire was designed to represent the several contents of the units; on the other, the instrument was developed with respect to the phases and processes of Zimmerman's self-regulation model [8], such as goal setting, strategic planning, intrinsic value, attention focusing, self-recording, self-evaluation, and causal attribution. These processes were chosen to represent the scales of the overall scale self-regulated learning. Following the model, the forethought phase was composed of the scales goal setting, strategic planning, and intrinsic value, with 13 items altogether. Regarding the performance or volitional control phase, two scales with nine items in total were composed which covered themes of attention focusing and self-recording. The self-reflection phase referred to the scales self-evaluation and causal attribution, which were measured by nine items. Altogether, the questionnaire consisted of 31 items. In Table 3, the reliabilities of the questionnaire are depicted for the measurements (pretest/posttest/follow-up measurement). The reliabilities of the posttest were regarded as criterion. Since Cronbach's alpha ranged between 0.61 and 0.85 , the reliability of the instrument can be rated as satisfactory $(\alpha>.60)$. As the study was designed for regular mathematics lessons, the scales were related to mathematics; for example, "Before I start with a mathematics task, I plan how to begin."

3.4.2. Learning Diary. In order to measure self-regulated learning on the state level, the students of the experimental group were also asked to fill out paper-and-pencil diaries for a period of six weeks. The items of the diary had to be filled out before and after performing homework tasks and were related to items of other instruments, which were already developed in this context (see $[43,54]$ ). As with the questionnaire, they corresponded to the phases of self-regulated learning and were presented in a closed format, coded on a four-point Likert-type scale, with scores ranging from 1 to 4 (1: I disagree, 2: I somewhat disagree, 3: I somewhat agree, and 4: I agree). Altogether, the students had to estimate 19 items which asked for their daily learning behavior at home. Therefore, the items were worded concerning the current learning behavior for that day. Before doing their homework, the students had to answer eight items with regard to the processes of the forethought phase (e.g., goal setting: "I know exactly what I want to learn today" or intrinsic value: "Today, I have a mind to learn"). After having finished their homework, they were asked to answer eleven items related to processes of the volitional control phase and the self-reflection phase (e.g., attention focusing: "Today I've learned very concentratedly" or self-recording: "Today while learning, I thought about my learning process").

A split-half reliability was calculated (odd-even coefficient) by dividing the days for each person into two groups, one with even numbers and one with odd numbers. The mean values of each person were correlated for the variables. Table 4 shows the detailed results for each self-regulatory variable, which was measured by the diary. All variables correlated highly significantly $(P<.001)$.

3.4.3. Mathematics Test. Additionally, the students had to work on a standardized mathematics test [62] consisting of eight tasks altogether, which dealt with arithmetic, calculations concerning practical problems, and geometry. As the students were asked to work on it before and after the intervention, two versions were administered which were similar regarding item difficulty (approximately $P_{i}=.67$ ) and item-scale correlation (approximately $r_{i(t-i)}=0.33$ ). The students were able to reach a maximum number of ten points.

3.4.4. Teacher's Register. As the training was carried out by teachers, it was interesting to measure teachers' evaluation of the learning materials including the instructions. The teachers' assessments of the learning materials were used as an indicator for the implementation of the materials. Therefore, a kind of teacher's register was handed out to teachers in order to evaluate each unit regarding design, applicability, and comprehensibility. With respect to a teacher's daily work routine, the evaluation system followed the German system of notation (1: very good, 2: good, 3: satisfactory, 4: adequate, 5: poor, and 6: insufficient). Additionally, the teachers were asked to estimate the motivation of their students while working on the learning materials (1: not motivated, 2: less motivated, 3: motivated, and 4: very motivated). A further function of this register was to give teachers an opportunity for feedback and suggestions for useful variations of the learning materials.

\section{Results}

Following the succession of the hypotheses, the results of the longitudinal data are reported firstly followed by the tests of time series hypotheses.

\subsection{Results of the Longitudinal Analyses}

4.1.1. Pre/Postanalysis of the Self-Regulation Questionnaire. The research questions postulated that training on selfregulated learning leads to an improvement of self-regulated learning variables. We expected no changes for the untrained 
TABLE 5: Descriptive data of the self-regulated learning variables and results for the interaction time $\times$ training.

\begin{tabular}{|c|c|c|c|c|c|c|}
\hline \multirow{2}{*}{$\begin{array}{c}\mathrm{DV} \\
\text { time } * \text { training }\end{array}$} & \multicolumn{4}{|c|}{$M(\mathrm{SD})$} & \multirow[b]{2}{*}{$F$} & \multirow[b]{2}{*}{$\eta^{2}$} \\
\hline & Group & Pretest & Posttest & $\mathrm{df}$ & & \\
\hline \multicolumn{7}{|l|}{ Overall scale } \\
\hline \multirow{2}{*}{ Self-regulated learning } & CG & $3.16(.40)$ & $3.02(.58)$ & 1,133 & $6.58^{*}$ & .05 \\
\hline & EG & $3.12(.42)$ & $3.16(.50)$ & & & \\
\hline \multicolumn{7}{|l|}{ Scales } \\
\hline \multirow{2}{*}{ Goal setting } & CG & $3.42(.45)$ & $3.42(.48)$ & 1,133 & $3.99^{*}$ & .03 \\
\hline & EG & $3.29(.55)$ & $3.46(.52)$ & & & \\
\hline \multirow{2}{*}{ Strategic planning ${ }^{\mathrm{a}}$} & CG & $3.38(.55)$ & $3.16(.71)$ & 1,133 & $5.74^{*}$ & .04 \\
\hline & EG & $3.12(.62)$ & $3.28(.59)$ & & & \\
\hline \multirow{2}{*}{ Intrinsic value } & CG & $3.17(.64)$ & $2.96(.71)$ & 1,133 & $6.68^{*}$ & .05 \\
\hline & EG & $3.35(.66)$ & $3.37(.64)$ & & & \\
\hline \multirow{2}{*}{ Attention focusing } & CG & $3.24(.50)$ & $3.13(.56)$ & 1,133 & .95 & .01 \\
\hline & EG & $3.26(.60)$ & $3.25(.65)$ & & & \\
\hline \multirow{2}{*}{ Self-recording ${ }^{\mathrm{a}}$} & CG & $3.33(.59)$ & $3.08(.78)$ & 1,133 & $4.51^{*}$ & .03 \\
\hline & EG & $3.12(.64)$ & $3.20(.66)$ & & & \\
\hline \multirow{2}{*}{ Self-evaluation } & CG & $2.88(.68)$ & $2.86(.79)$ & 1,133 & .03 & .00 \\
\hline & EG & $2.94(.61)$ & $2.90(.85)$ & & & \\
\hline \multirow{2}{*}{ Causal attribution } & CG & $3.08(.67)$ & $3.00(.64)$ & 1,133 & 1.19 & .01 \\
\hline & EG & $3.06(.61)$ & $3.12(.61)$ & & & \\
\hline
\end{tabular}

CG: control group $(N=72)$; EG: experimental group $(N=63)$.

${ }^{a}$ Because of pretest differences, MANCOVA with pretest values as covariate was conducted.

${ }^{*} P<.05$.

group (control group). The differences between the experimental group and control group were calculated by means of analyses of variance, with time as a repeated measurement factor. As it was not possible to randomly assign the students to the conditions, the pretest differences were controlled first. Regarding self-regulated learning variables, significant pretest differences between the groups were found for the scales strategic planning, $t(133)=2.57, P=.01, d=.43$, and self-recording, $t(133)=2.09, P=.04, d=.34$. As can be seen, the students of the experimental group reported higher pretest values than the students of the control group did (see Table 5). Because of these pretest differences, analyses of covariance with the pretest value as covariate were conducted to control these differences. Table 5 gives an overview of the results of interaction time $\times$ training, as well as means and standard deviations for the overall scale and the scales. The results indicate a significant interaction effect for the overall scale self-regulated learning, $F(1,133)=6.58, P=.01, \eta^{2}=$ .05 , as well as for the scales goal setting, $F(1,133)=3.99$, $P=.04, \eta^{2}=.03$, and intrinsic value, $F(1,133)=6.68, P=$ $.01, \eta^{2}=.05$. There were no significant interaction effects for the scales attention focusing, self-evaluation, and causal attribution. Regarding strategic planning and self-recording, the results of the analysis of covariance showed significant effects for both scales (strategic planning: $F(1,133)=5.74$, $P=.02, \eta^{2}=.04$; self-recording: $F(1,133)=4.51, P=.04$, $\left.\eta^{2}=.03\right)$.

Regarding the overall scale self-regulated learning, there was a small nonsignificant increase among the students of the experimental group, whereas a significant decline was found for the students of the control group, $t(71)=3.36$,
$P=.001, d=0.41$. With respect to the self-regulated learning variables, this significant decline for the students of the control group was also detected for the scales strategic planning, $t(71)=2.73, P=.01, d=0.32$, intrinsic value, $t(71)=4.06, P=.00, d=0.49$, and self-recording, $t(71)=$ $2.82, P=.01, d=0.33$. For the students of the experimental group, there was a significant increase concerning the scale goal setting, $t(61)=-2.28, P=.03, d=0.28$. Figure 2 presents the results for the students' self-regulated learning and mathematical achievement separately for experimental and control group.

4.1.2. Pre/Postanalysis of the Mathematics Test. Regarding the mathematical competencies of the students, the experimental group as well as the control group should improve their mathematics achievement because both groups were continuously taught in mathematics. However, the experimental group should benefit from training on self-regulated learning strategies in terms of a greater increase in their mathematics achievement. The results of the $t$-test showed that the mathematical competencies of both groups were improved after the training period (see Figure 2). Regarding the effect size, the experimental group showed a stronger increase, $t(62)=-5.29, P=.00, d=.68$, than the control group, $t(71)=-2.61, P=.01, d=.31$.

In addition, it was examined if a training effect could be found. As there were significant pretest differences between the groups of the overall measure (sum over all tasks of the test), an analysis of variance was conducted with pretest values as covariate. The results showed no significant training effect. 


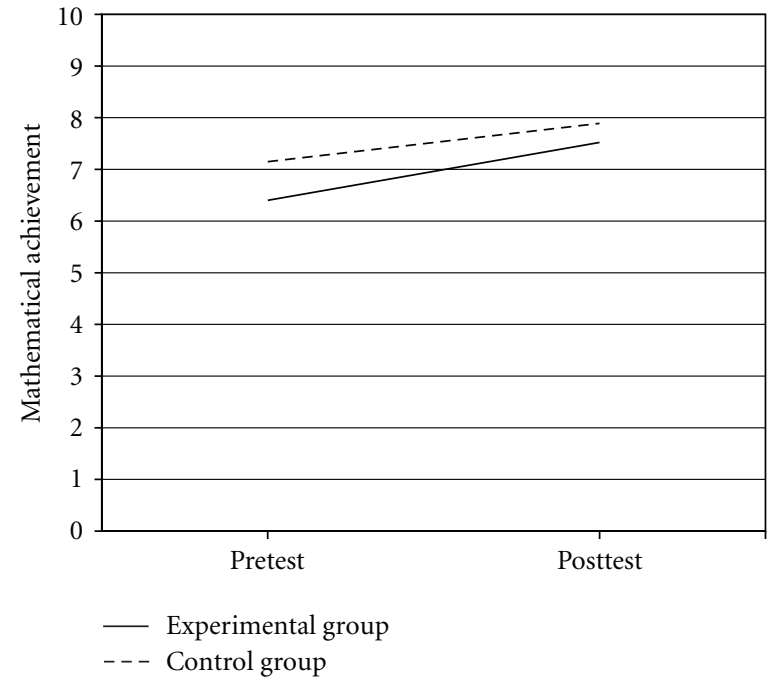

(a)

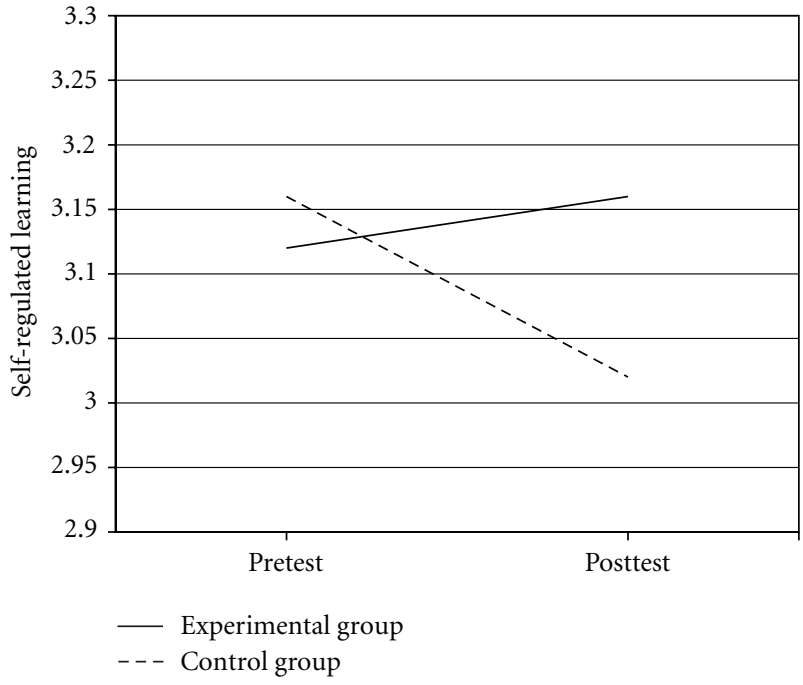

(b)

FIGURE 2: Interaction time $\times$ group for the overall scale self-regulated learning as well as for mathematical achievement. Mathematical achievement measures could take values from 0 to 10; self-regulated learning was rated on a four-point scale.

4.1.3. Follow-Up Measurement. The students of the experimental group received the same questionnaire again in order to measure the stability of the training's effect after a period of twelve months. The data of the variables should be stable, which means that no significant additional effects were expected and that the values should not decrease significantly. Therefore, the assumption that there were no changes regarding goal setting, strategic planning, intrinsic value, self-recording, self-evaluation, attention focusing, causal attribution, and the overall scale self-regulated learning was tested and the alpha-level was increased to $20 \%$ [63]. In general, results show that the variables did not change significantly between the posttest and the follow-up measurement. Table 6 shows the detailed results for the scales as well as for the overall scale self-regulated learning.

\subsection{Results of the Training Evaluation Based on Process Data.} In order to describe the training evaluation based on process data of the experimental group, interrupted time series were conducted for the trained self-regulated learning variables related to the units of the learning materials and trend analyses were conducted for the untrained variables selfefficacy, self-recording, and self-evaluation. As $70 \%$ of the diaries were filled out with more than 22 data points $(>73 \%)$, data for the variables of the learning diary were aggregated from 44 students and included into analyses. Therefore, the mean of the variable computed across all participants could be generated for each day. In order to examine the training effects for the components related to the units based on the learning diary data, a multiple baseline design was used and interrupted time series analyses were conducted. Step functions were expected to show an immediate impact and to continue over the long term. In order to analyze ARMA processes, the residuals were used [64]. With the residual data, autocorrelations and partial autocorrelations were conducted to identify ARMA processes.
In Table 7, the results for the trained variables of each unit are depicted. The first column represents the subscales of the diary. The $b_{0}$ score shows the intercepts for the variable as an indicator for the basic level, whereas $b_{1}$ is the indicator for the change level. Using the $t$-score, the means before (baseline) and after the training can be analyzed to expose changes. The ARMA model describes how the level of the variable, measured at a previous point in time, influences the same variable at a following point in time. The number of terms in autoregressive (AR) terms of the model reports the dependency among successive observations. Thereby, each term has an associated correlation coefficient that describes the magnitude of this dependency. With regard to the moving average (MA) terms, the model represents the persistence of a random shock from one observation to the next. After the model estimation, (partial) autocorrelations were computed in order to test white noise residuals (with Ljung-Box-Q test).

The results showed that after the first training unit, students reported having been able to improve their goal setting strategies $(t=4.64, P=.00)$. The second unit caused no enhancement with respect to the variable strategic planning. After the third unit, the variable intrinsic value improved significantly $(t=2.65, P=.01)$. In contrast, with respect to the variables attention focusing and causal attribution, there were no effects of the fourth and fifth units. However, the variable causal attribution showed AR (1) process. For the other variables, there were no dependencies among successive observations (white noise).

Additionally, trend analyses were conducted for the variables that were not explicitly trained but should have been influenced by the intervention. Because of the reactivity effect (see [65-67]), positive linear trends were expected for the nontrained variables self-efficacy, self-recording, and self-evaluation, as well as for the overall scale selfregulated learning. Regarding the variables self-efficacy and 
TABLE 6: Results of the $t$-tests for follow-up measurements of the experimental group.

\begin{tabular}{|c|c|c|c|c|c|c|}
\hline \multirow[b]{2}{*}{ Scale } & \multicolumn{2}{|c|}{$M(\mathrm{SD})$} & \multirow[b]{2}{*}{$\mathrm{df}$} & \multirow[b]{2}{*}{$t^{\mathrm{a}}$} & \multirow[b]{2}{*}{$P$} & \multirow[b]{2}{*}{$d$} \\
\hline & Posttest & Followup & & & & \\
\hline Goal setting & $3.47(.51)$ & $3.44(.53)$ & 57 & .49 & .62 & .15 \\
\hline Strategic planning & $3.29(.58)$ & $3.16(.60)$ & 57 & 1.41 & .16 & .18 \\
\hline Intrinsic value & $3.39(.62)$ & $3.46(.55)$ & 57 & -.84 & .40 & .11 \\
\hline Attention focusing & $3.27(.62)$ & $3.15(.53)$ & 57 & 1.69 & .10 & .21 \\
\hline Self-recording ${ }^{\mathrm{b}}$ & $3.21(.67)$ & $3.06(.73)$ & 57 & 1.63 & .11 & .22 \\
\hline Self-evaluation & $2.93(.83)$ & $2.83(.76)$ & 57 & .92 & .36 & .12 \\
\hline Causal attribution & $3.11(.61)$ & $3.04(.61)$ & 57 & .65 & .52 & .09 \\
\hline \multicolumn{7}{|l|}{ Overall scale } \\
\hline Self-regulated learning & $3.16(.46)$ & $3.08(.40)$ & 57 & 1.49 & .14 & .19 \\
\hline
\end{tabular}

$N=58$ (three students were absent on the day of the follow-up measurement); $d$ : effect size.

a - indicates an increase, +indicates a decrease.

TABLE 7: Results of the interruption time series analysis to examine the effects of the intervention.

\begin{tabular}{lccccc}
\hline & $b_{0}$ & $b_{1}$ & $t$ & ARMA models & ARMA parameter \\
\hline Kickoff: baseline & & & & & \\
1st unit: goal setting & 2.91 & .66 & $4.64^{* *}$ & W.N. & \\
2nd unit: strategic planning & 3.39 & .18 & .98 & W.N. & W.N. \\
3rd unit: intrinsic value & 3.12 & .45 & $2.65^{*}$ & W.N. & .68 \\
4th unit: attention focusing & 3.48 & .11 & .58 & AR $(1,0)$ & $4.86^{* *}$ \\
5th unit: causal attribution & 3.61 & -.24 & -1.31 &
\end{tabular}

$b_{0}$ : basic value, $b_{1}$ : change; W.N.: white noise.

${ }^{*} P<.05,{ }^{* *} P<.01$.

self-evaluation, there were no significant changes, whereas significant linear trends were found with respect to selfrecording $\left(P=.04 ; b_{0}=3.07 ; b_{1}=.01 ; \mathrm{RSQ}=.14\right)$ and selfregulated learning $\left(P=.03 ; b_{0}=3.31 ; b_{1}=.01 ; \mathrm{RSQ}=.16\right)$. Thereby, the time trend over a period of 30 days could explain $14 \%$ of the variance of self-recording and $16 \%$ of the variance of self-regulated learning. Figure 3 shows the results for the linear trend of the overall scale self-regulated learning.

4.3. Teachers' Evaluation of the Learning Materials. The teachers' assessment of the learning materials regarding their design, application, and comprehensibility ranged between 1.60 and 1.67 (design: $M=1.60, \mathrm{SD}=.72$; applicability: $M=1.73, \mathrm{SD}=.95$; comprehensibility: $M=1.67$, $\mathrm{SD}=.61)$. The students' motivation while working on the learning materials was estimated with a mean value of 3.30 $(S D=.62)$. Based on these results, the implementation of the learning materials should be carried out successfully.

\section{Discussion}

The aim of the intervention was the enhancement of fourth grade students' self-regulated learning by working on interdisciplinary teaching materials, which were related to particular strategies of Zimmerman's self-regulation model [8]. By means of analyses of variance with time as repeated measurement factor, significant interaction effects were found for the overall scale self-regulated learning, as well as

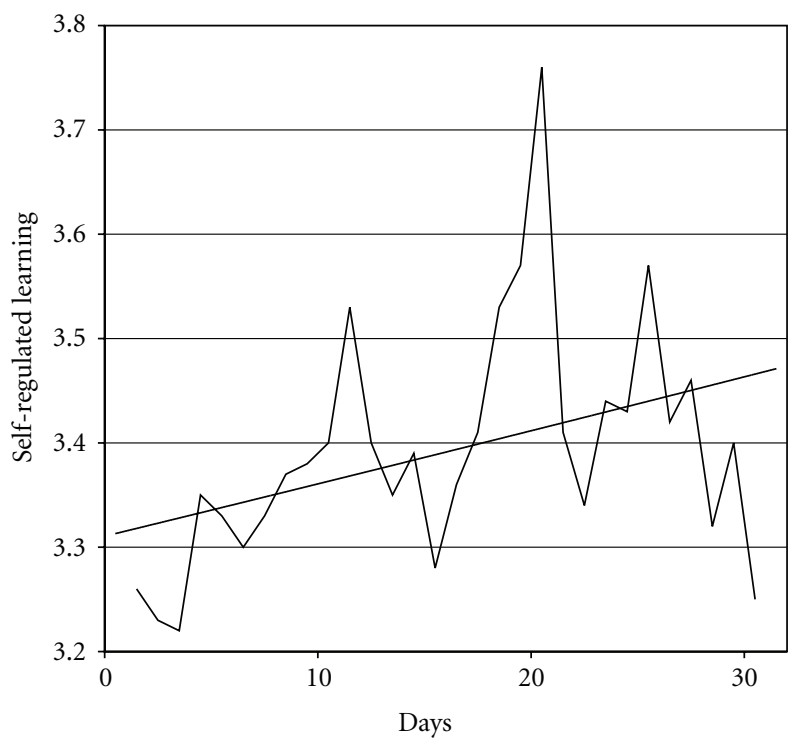

FIGURE 3: Trajectory and linear trend for self-regulated learning measured on a four-point scale.

for the scales goal setting, intrinsic value, strategic planning, and self-recording.

Regarding the results within the groups, it could be pointed out that the overall scale self-regulated learning 
did not change in the expected direction. Instead of a significant increase for the experimental group, there was a significant decrease for the control group, whereas for the experimental group the overall scale remained stable. Regarding the experimental group, this result for the overall scale was supported by the results of the scales strategic planning, intrinsic value, attention focusing, self-recording, self-evaluation, and causal attribution. Except for the scale goal setting, a significant increase was found as expected. For the control group, the results of the scales strategic planning, intrinsic value, and self-recording showed a significant decline as did the overall scale self-regulated learning. Twelve months after training, the students of the experimental group filled out the same questionnaire again, in order to measure stability of intervention effects. There should be no significant change of the data according to an increase or decline. The results show that all scales were stable after a period of twelve months.

Besides the improvement in students' self-regulated learning, we also expected an effect with respect to students' mathematical achievement. As the learning materials were related to mathematical contents and implemented during regular mathematics lessons, we dealt with the question of whether there was a supportive effect of self-regulated learning on students' mathematics achievement [5]. Regarding the effects between the groups, no significant interaction effect was found. The results showed an enhancement for the experimental group as well as for the control group. As both groups have been taught mathematics, this increase was not unexpected. Regarding the effects within the groups, we expected a greater increase in mathematics achievement for the experimental group than for the control group. With respect to the effect sizes, the students of the experimental group showed better improvement in their mathematics achievement than the control group did. These results were in line with Perels et al. [49]. In their study, they also found an improvement for both groups, but a greater increase for the students belonging to the experimental group.

On the level of process data, interrupted time series analyses indicated an increase in value of some of the trained variables in the expected direction after the training. In detail, this was the case for the variable goal setting after the second unit, as well as for the variable intrinsic value after the fourth unit. Regarding strategic planning, attention focusing, and causal attribution no significant changes were found. Additionally, linear trends were performed for the nontrained variables self-efficacy, self-recording, and selfevaluation, as well as for the overall scale self-regulated learning. Although these variables were not part of the training, the students had to answer items corresponding to them by filling out the diary each day. Therefore, we expected an influence in terms of the reactivity effect $[27,65]$. Regarding the scale self-recording and the overall scale selfregulated learning, significant linear trends were found as expected whereas there were no trends for the variables selfefficacy and self-evaluation. The absent linear trends for these variables are in contrast to the results of other studies (see, e.g., $[43,67])$. Therefore, the postulated reactivity effect [65] has to be considered critically because evidence for it was limited. In this study, the learning diary primarily seemed to serve as an evaluation instrument and not as a part of the intervention.

In summary, the results lead to the assumption that the learning materials seemed to be beneficial with regard to fourth grade students' self-regulated learning and mathematics achievement. However, the results of the pretest and posttest measurements for self-regulated learning have to be discussed critically. Regarding the experimental group, there was only a small, nonsignificant increase found for the overall scale and the scales strategic planning, intrinsic value, attention focusing, self-recording, self-evaluation, and causal attribution. Additionally, no interaction effects were found for the variables attention focusing, self-evaluation, and causal attribution. As the variables self-recording and self-evaluation were not involved as part of the training, this result was not unexpected. Obviously, it was not possible to improve these variables by training other specific processes of self-regulated learning. With respect to the other variables, the lack of effects was not expected. It can be discussed as to whether there was enough time to practice and transfer the strategies of these units, which were very complex. The students worked on the teaching materials for the duration of one lesson per week and had to deal with one task per training session. It would probably have been useful if the students had worked on more than one task during each training session to make sure that they transferred the learned strategies to their everyday work. Furthermore, it may be possible that the imparted strategies initially interfere with already existing strategies [68]. As the study was realized at grade four, the students may already have developed their own strategies to regulate their learning behavior. Greater effects might be expected when there is a continuous and fairly long-term instruction of self-regulated learning in regular classes [69].

Moreover, there are limiting factors and unanswered questions regarding this study: for the assessment of selfregulated learning, only self-report methods (questionnaire and learning diary) were used. These self-report methods only measured students' evaluation of their use of strategies, but not their actual use [70]. In future research, multimethod approaches should be used. In this study, the students were also videotaped during regular mathematics lessons (before and after the intervention phase). For further analysis, the observation data has to be analyzed and referred to the results of the self-report data. Consequently, it will be possible to analyze if students actually used the self-regulated learning strategies supported by the learning materials. In this context, also other on-line methods like thinking-aloud protocols might be of interest (see [71]).

Additionally, there is another question concerning the measurement of self-regulated learning. By using learning diaries, we were able to assess and analyze students' selfregulated learning on a daily basis. Following Schmitz and Wiese [9], we used this data as process data to conduct time series analysis. This approach has to be regarded critically because learning diaries represent self-report measurements. It has to be questioned to which extent this data could be concerned as process data. 
Another limitation concerns the state aspect of Zimmerman's model [8]. He postulated that self-regulation is an adaptable and cumulative process. According to these assumptions, his self-regulation model tends to focus on state aspects of self-regulation. However, in the study we used self-report data, which rather concerns trait aspects of self-regulation. Thus, there is a discrepancy between the theoretical framework of the study and the chosen assessment methods. However, other authors, such as Schmidt [54] or Hong and O'Neil [72], regard self-regulation at both the state and trait levels. They hypothesize that academic self-regulation consists of transitory (meta)cognitive states and relatively stable (meta)cognitive traits. For example, students with high self-regulatory traits tend to use their metacognitive skills more effectively than students with low trait self-regulation [73]. Hong [74] compared state and trait self-regulation models and came to the conclusion that every self-regulation state refers to a general trait component (see also [75]). Furthermore, she reported high correlations between state and trait constructs (see also [76]). Therefore, analyzing self-regulatory traits by using questionnaire data makes assumptions about self-regulatory states, as postulated in Zimmerman's self-regulation model [8].

Furthermore, the implementation of the developed learning materials has to be discussed because the contents of the units were imparted by the teachers themselves. From the teachers' point of view, the learning materials and the instructions were evaluated as very good to good with respect to design, applicability, and comprehensibility. Furthermore, the teachers estimated the motivation of their students while working on the learning materials to be very positive. These estimations indicate that the developed teaching materials could be successfully implemented in the regular classroom situation. In fact, an innovation such as these learning materials can be evaluated as being successfully introduced as soon as the teachers have adopted it [77]. Adoption in this context means that the teachers are able and willing to implement an innovation into their lessons. Moreover, they have to feel confident in their ability to adapt it to the needs and abilities of their students. Following Bitan-Friedlander et al. [78], teachers' adoption of an innovation in the educational field depends on "agreeing with the theoretical content and with the pedagogical value of the innovation" [78, page 617]. The extent to which an innovation might be adopted by a teacher can be defined in terms of the teacher's personal concerns. In the present study, the teachers expressed being excited about the learning materials. However, there were no other clues as to what extent the teachers were involved and motivated to work with the learning materials. For further studies, this might be an interesting and helpful approach.

Another limitation refers to the question of how the students were assigned to the experimental and the control group. As the learning materials needed to be implemented by teachers into students' regular learning environment, it was not possible to realize a randomized assignment of the students to experimental and control group. Therefore, students' pretest values of self-regulated learning and mathematical achievement were controlled.
Finally, the significant interaction effect for the overall scale self-regulated learning and the scales goal setting, intrinsic value, strategic planning, and self-recording mainly occurred due to the significant decline of the control group. This decline was not expected and cannot be explained in the framework of this study. For further intervention research, it might be worthwhile to assess more information concerning the control group.

In this context, it also might be of interest to design an intervention which involves more or even all of the postulated strategies of Zimmerman's self-regulation model [8]. In our study, there had to be a focus on the selected strategies for two reasons. Firstly, the (meta)cognitive abilities of the target group had to be considered (see [40]). Secondly, the duration of the intervention was determined because the learning materials were implemented into regular mathematics lessons. This implied that the more time was spent on the learning materials, the less time could be spent on the regular mathematics contents. Therefore, and for developmental psychological reasons, the intervention was reduced to six units. However, the study involved both (meta)cognitive and motivational aspects of self-regulated learning corresponding to the three learning phases of Zimmerman's model [8]. This represents an advantage of the study in contrast to other trainings which focused either on (meta)cognitive or motivational components (for an overview, see [79]).

In summary, present findings show that it is possible to maintain a rather high level of self-regulated learning by using self-regulated learning materials which were implemented by teachers. To our opinion it is worth emphasizing that the embedding of specific self-regulated learning strategies into regular mathematics lessons was not at the cost of students' mathematical achievement, but supported it. Thus, it might be assumed that if an improvement of students' selfregulated learning occurs, this improvement might be related to improvements in mathematical achievement. Further studies should investigate if and under what conditions this assumption holds true. Therefore, the learning materials should be optimized and the evaluation instruments adapted to other subjects.

The present study implies practical consequences of creating powerful learning environments for supporting selfregulated learning. As the results show, it is possible to embed self-regulated learning strategies in regular lessons by using interdisciplinary learning materials. As self-regulated learning represents an important factor for academic and lifelong learning [80], teaching these strategies should be integrated into regular elementary school lessons in order to improve the development of advantageous learning behavior as early as possible.

\section{Acknowledgment}

This research was supported by grants from the DFG (German Research Foundation).

\section{References}

[1] M. Boekaerts, P. R. Pintrich, and M. Zeidner, "Self-regulation. An introductory overview," in Handbook of Self-Regulation, 
M. Boekaerts, P. R. Pintrich, and M. Zeidner, Eds., pp. 1-9, Academic Press, San Diego, Calif, USA, 2000.

[2] A. Bandura, "The primacy of self-regulation in health promotion," Applied Psychology, vol. 54, no. 2, pp. 245-254, 2005.

[3] B. J. Zimmerman, "Investigating self-regulation and motivation: historical background, methodological developments, and future prospects," American Educational Research Journal, vol. 45, no. 1, pp. 166-183, 2008.

[4] P. R. Pintrich and E. V. De Groot, "A motivational science perspective on the role of student motivation in learning and teaching contexts," Journal of Educational Psychology, vol. 95, no. 4, pp. 667-686, 2003.

[5] L. Nota, S. Soresi, and B. J. Zimmerman, "Self-regulation and academic achievement and resilience: a longitudinal study," International Journal of Educational Research, vol. 41, no. 3, pp. 198-215, 2004.

[6] B. J. Zimmerman and A. Bandura, "Impact of self-regulatory influences on writing course attainment," American Educational Research Journal, vol. 31, no. 4, pp. 845-862, 1994.

[7] M. Boekaerts, "Self-regulated learning: where we are today," International Journal of Educational Research, vol. 31, no. 6, pp. 445-457, 1999.

[8] B. J. Zimmerman, "Attaining self-regulation: a social cognitive perspective," in Handbook of Self-Regulation, M. Boekaerts, P. R. Pintrich, and M. Zeidner, Eds., pp. 13-41, Academic Press, San Diego, Calif, USA, 2000.

[9] B. Schmitz and B. S. Wiese, "New perspectives for the evaluation of training sessions in self-regulated learning: time-series analyses of diary data," Contemporary Educational Psychology, vol. 31, no. 1, pp. 64-96, 2006.

[10] P. R. Pintrich, "The role of goal orientation in self-regulated learning," in Handbook of Self-Regulation, M. Boekaerts, P. R. Pintrich, and M. Zeidner, Eds., pp. 451-502, Academic Press, San Diego, Calif, USA, 2000.

[11] E. A. Locke and G. P. Latham, "Building a practically useful theory of goal setting and task motivation: a 35-year odyssey," American Psychologist, vol. 57, no. 9, pp. 705-717, 2002.

[12] S. Schreblowski and M. Hasselhorn, "Selbstkontrollstrategien: Planen, Überwachen, Bewerten [Metacognitive control strategies: Planning, monitoring, valuing]," in Handbuch Lernstrategien, H. Mandl and H. F. Friedrich, Eds., pp. 252161, Hogrefe, Göttingen, Germany, 2006.

[13] E. A. Locke and G. P. Latham, "What should we do about motivation theory? Six recommendations for the twenty-first century," Academy of Management Review, vol. 29, no. 3, pp. 388-403, 2004.

[14] D. H. Schunk, P. R. Pintrich, and J. L. Meece, Motivation in Education. Theory, Research, and Applications, Pearson, New Jersey, NJ, USA, 3rd edition, 2008.

[15] B. J. Zimmerman, "Self-efficacy: an essential motive to learn," Contemporary Educational Psychology, vol. 25, no. 1, pp. 8291, 2000.

[16] F. Pajares, "Motivational role of self-efficacy beliefs in selfregulated learning," in Motivation and Self-Regulated Learning. Theory, Research, and Application, D. H. Schunk and B. J. Zimmerman, Eds., pp. 111-139, Routledge, New York, NY, USA, 2007.

[17] E. L. Deci and R. M. Ryan, "The "what" and "why" of goal pursuits: human needs and the self-determination of behavior," Psychological Inquiry, vol. 11, no. 4, pp. 227-268, 2000.

[18] M. Dowson and D. M. McInerney, "What do students say about their motivational goals?: towards a more complex and dynamic perspective on student motivation," Contemporary Educational Psychology, vol. 28, no. 1, pp. 91-113, 2003.
[19] J. M. Harackiewicz, K. E. Barron, P. R. Pintrich, A. J. Elliot, and T. M. Thrash, "Revision of achievement goal theory: necessary and illuminating," Journal of Educational Psychology, vol. 94, no. 3, pp. 638-645, 2002.

[20] C. Ames, "Achievement goals and the classroom motivational climate," in Student Perceptions in the Classroom, D. H. Schunk and J. L. Meece, Eds., pp. 327-348, Lawrence Erlbaum Associates, Hillsdale, NJ, USA, 1992.

[21] G. Dreisbach and H. Haider, "How task representations guide attention: further evidence for the shielding function of task sets," Journal of Experimental Psychology, vol. 35, no. 2, pp. 477-486, 2009.

[22] F. Wieber, A. von Suchodoletz, T. Heikamp, G. Trommsdorff, and P. M. Gollwitzer, "If-then planning helps school-aged children to ignore attractive distractions," Social Psychology, vol. 42, no. 1, pp. 39-47, 2011.

[23] L. Corno, "The best-laid plans. Modern conceptions of volition and educational research," Educational Researcher, vol. 22, no. 2, pp. 14-22, 1993.

[24] J. Kuhl, "Action control: the maintenance of motivational states," in Motivation, Intention and Volition, F. Halisch and J. Kuhl, Eds., pp. 279-291, Springer, Berlin, Germany, 1985.

[25] D. H. Schunk, "Progress self-monitoring. Effects on children's self-efficacy and achievement," Journal of Experimental Education, vol. 51, pp. 89-93, 1983.

[26] K. D. Vohs and B. J. Schmeichel, "Self-regulation: how and why people reach (and fail to reach) their goals," in The Self, C. Sedikides and S. J. Spencer, Eds., pp. 139-162, Psychology Press, New York, NY, USA, 2007.

[27] W. J. Korotitsch and R. O. Nelson-Gray, "An overview of self-monitoring research in assessment and treatment," Psychological Assessment, vol. 11, no. 4, pp. 415-425, 1999.

[28] A. Bandura, Social Foundations of Thought and Action: A Social Cognitive Theory, Prentice-Hall, Englewood Cliffs, NJ, USA, 1986.

[29] C. Schöne, O. Dickhäuser, B. Spinath, and J. StiensmeierPelster, "Goal orientation and reference-norm orientation: two related constructs?" Zeitschrift für Pädagogische Psychologie, vol. 18, no. 2, pp. 93-99, 2004.

[30] M. Dresel and A. Ziegler, "Langfristige Förderung von Fähigkeitsselbstkonzept und impliziter Fähigkeitstheorie durch computerbasiertes attributionales Feedback [Long-term enhancement of academic self-concept and implicit ability theory through computer-based attributional feedback]," Zeitschrift für Pädagogische Psychologie, vol. 20, pp. 49-63, 2006.

[31] B. J. Zimmerman and A. Kitsantas, "Developmental phases in self-regulation: shifting from process goals to outcome goals," Journal of Educational Psychology, vol. 89, no. 1, pp. 29-36, 1997.

[32] B. J. Zimmerman and T. J. Cleary, “Adolescents' development of personal agency: the role of self-efficacy beliefs and selfregulatory skill," in Self-Efficacy Beliefs of Adolescents, F. Pajares and T. C. Urdan, Eds., pp. 71-96, Information Age Publishing, Greenwich, UK, 2006.

[33] M. Boekaerts and E. Cascallar, "How far have we moved toward the integration of theory and practice in self-regulation?" Educational Psychology Review, vol. 18, no. 3, pp. 199210, 2006.

[34] M. Boekaerts, "Self-regulated learning: a new concept embraced by researchers, policy makers, educators, teachers, and students," Learning and Instruction, vol. 7, no. 2, pp. 161-186, 1997. 
[35] D. Leutner, A. Barthel, and B. Schreiber, "Students can learn to motivate themselves for learning - a training experiment," Zeitschrift für Pädagogische Psychologie, vol. 15, no. 3-4, pp. 155-167, 2001.

[36] F. Perels, T. Gürtler, and B. Schmitz, "Training of selfregulatory and problem-solving competence," Learning and Instruction, vol. 15, no. 2, pp. 123-139, 2005.

[37] C. Leopold, V. den Elzen-Rump, and D. Leutner, "Selfregulated learning from science texts," in Studies on the Educational Quality of Schools. The Final Report on the DFG Priority Programme, M. Prenzel, Ed., pp. 221-228, Waxmann, Münster, Germany, 2007.

[38] E. Souvignier and J. Moklesgerami, "Using self-regulation as a framework for implementing strategy instruction to foster reading comprehension," Learning and Instruction, vol. 16, no. 1, pp. 57-71, 2006.

[39] A. S. Labuhn, S. Bögeholz, and M. Hasselhorn, "Fostering learning through stimulation of self-regulation in science lessons," Zeitschrift für Pädagogische Psychologie, vol. 22, no. 1, pp. 13-24, 2008.

[40] M. B. Bronson, Self-Regulation in Early Childhood: Nature and Nurture, Guilford Press, New York, NY, USA, 2000.

[41] N. Eisenberg, C. L. Smith, A. Sadovsky, T. L. Spinrad, R. F. Baumeister, and K. D. Vohs, "Effortful control: Relations with emotion regulation, adjustment, and socialization in childhood," in Handbook of Self-Regulation: Research, Theory, and Applications, R. F. Baumeister and K. D. Vohs, Eds., pp. 259-282, Guilford Press, New York, NY, USA, 2004.

[42] C. Dignath and G. Büttner, "Components of fostering self-regulated learning among students. A meta-analysis on intervention studies at primary and secondary school level," Metacognition and Learning, vol. 3, no. 3, pp. 231-264, 2008.

[43] B. Otto, SELVES-Schüler-, Eltern-und Lehrertraining zur Vermittlung effektiver Selbstregulation, Logos, Berlin, Germany, 2007, [SELVES - student, parents, and teacher training to impart effective self-regulation].

[44] N. Spörer and J. C. Brunstein, "Erfassung selbstregulierten Lernens mit Selbstberichtsverfahren. Ein Überblick zum Stand der Forschung [Assessing self-regulated learning with selfreport measurements: a state-of-the-art review]," Zeitschrift für Pädagogische Psychologie, vol. 20, no. 3, pp. 147-160, 2006.

[45] F. Perels, M. Merget-Kullmann, M. Wende, B. Schmitz, and C. Buchbinder, "Improving self-regulated learning of preschool children: evaluation of training for kindergarten teachers," British Journal of Educational Psychology, vol. 79, no. 2, pp. 311-327, 2009.

[46] C. Dignath, G. Büttner, and H. P. Langfeldt, "How can primary school students learn self-regulated learning strategies most effectively? A meta-analysis on self-regulation training programmes," Educational Research Review, vol. 3, no. 2, pp. 101-129, 2008.

[47] L. S. Fuchs, D. Fuchs, K. Prentice et al., "Enhancing thirdgrade students' mathematical problem solving with selfregulated learning strategies," Journal of Educational Psychology, vol. 95, no. 2, pp. 306-315, 2003.

[48] J. S. Rozendaal, A. Minnaert, and M. Boekaerts, "The influence of teacher perceived administration of self-regulated learning on students' motivation and information-processing," Learning and Instruction, vol. 15, no. 2, pp. 141-160, 2005.

[49] F. Perels, C. Dignath, and B. Schmitz, "Is it possible to improve mathematical achievement by means of self-regulation strategies? Evaluation of an intervention in regular math classes," European Journal of Psychology of Education, vol. 24, no. 1, pp. 17-31, 2009.
[50] J. Hattie, J. Biggs, and N. Purdie, "Effects of learning skills interventions on student learning: a meta-analysis," Review of Educational Research, vol. 66, no. 2, pp. 99-136, 1996.

[51] E. De Corte, L. Mason, F. Depaepe, and L. Verschaffel, "Self-regulation of mathematical knowledge and skills," in Handbook of Self-Regulation of Learning and Performance, B. J. Zimmerman and D. H. Schunk, Eds., pp. 155-172, Routledge, New York, NY, USA, 2011.

[52] E. De Corte, L. Verschaffel, and C. Masui, "The CLIA-model: a framework for designing powerful learning environments for thinking and problem solving," European Journal of Psychology of Education, vol. 19, no. 4, pp. 365-384, 2004.

[53] M. V. J. Veenman, J. J. Elshout, and J. Meijer, “The generality vs domain-specificity of metacognitive skills in novice learning across domains," Learning and Instruction, vol. 7, no. 2, pp. 187-209, 1997.

[54] M. Schmidt, How to Manage your PhD Thesis. Development of a Process Model of Self-Regulation to Foster Postgraduate Students, Dr. Kovac, Hamburg, Germany, 2009.

[55] T. Gürtler, Trainingsprogramm zur Förderung selbstregulativer Kompetenz in Kombination mit Problemlösestrategien PROSEKKO [Training program for the improvement of problem solving and self-regulating competencies] (Dissertation, TU Darmstadt), 2003.

[56] R. Pekrun, T. Goetz, A. C. Frenzel, P. Barchfeld, and R. P. Perry, "Measuring emotions in students' learning and performance: the Achievement Emotions Questionnaire (AEQ)," Contemporary Educational Psychology, vol. 36, no. 1, pp. 36-48, 2011.

[57] S. Bruder, Die Förderung von Selbstregulation bei Kindern unter Einbezug ihrer Eltern. Die Entwicklung, Durchführung und Evaluation eines Elterntrainings zur Förderung selbstregulierten Lernens in Verbindung mit der Adaption eines Schülertrainings für die Sekundarstufe I [Promotion of children's self-regulation integrating their parents] (Dissertation, TU Darmstadt), 2006.

[58] S. Loucks-Horsley, K. E. Stiles, S. Mundry, N. Love, and P. W. Hewson, Designing Professional Development for Teachers of Science and Mathematics, Corwin Press, Thousand Oaks, Calif, USA, 3rd edition, 2010.

[59] R. Schwarzer and G. S. Schmitz, "Collective efficacy of teachers: a longitudinal study in ten German states," Zeitschrift fur Sozialpsychologie, vol. 30, no. 4, pp. 262-274, 1999.

[60] K. P. Wild, U. Schiefele, and A. Winteler, Inventar zur Erfassung von Lernstrategien im Studium [Learning and Study Strategies Inventory], Universität der Bundeswehr, Institut für Erziehungswissenschaft und Pädagogische Psychologie, München, Germany, 1992.

[61] R. Schwarzer and M. Jerusalem, Skalen zur Erfassung von Lehrer-und Schülermerkmalen. Dokumentation der psychometrischen Verfahren im Rahmen der Wissenschaftlichen Begleitung des Modellversuchs Selbstwirksame Schulen [Scales for the assessment of student and teacher characteristics], Freie Universität Berlin, Berlin, Germany, 1999.

[62] T. Roick, D. Gölitz, and M. Hasselhorn, Deutscher Mathematiktest für dritte Klassen [German Mathematics Test for ThirdGraders] (DEMAT 3+), Beltz Test, Göttingen, Germany, 2004.

[63] J. Bortz, Statistik für Human-und Sozialwissenschaftler [Statistics for Human and Social Sientists], Springer, Heidelberg, Germany, 2005.

[64] B. Schmitz, "Univariate and multivariate time-series models: the analysis of intraindividual variability and intraindividual relationships," in Statistical Methods in Longitudinal Research 
(Vol. II: Time Series and Categorical Longitudinal Data), A. V. Eye, Ed., Academic Press, New York, NY, USA, 1990.

[65] J. Webber, B. Scheuermann, C. McCall, and M. Coleman, "Research on self-monitoring as a behavior management technique in special education classrooms: a descriptive review," RASE: Remedial \& Special Education, vol. 14, no. 2, Article ID 56, pp. 38-56, 1993.

[66] T. Hascher and L. Wepf, "Lerntagebücher im Praktikum von Lehramtsstudierenden [Use of learning diaries in the internship of student teachers]," Empirische Pädagogik, vol. 21, no. 2, pp. 101-118, 2007.

[67] B. Schmitz, "Self-Monitoring zur Unterstützung des Transfers einer Schulung in Selbstregulation für Studierende [Selfmonitoring to support the transfer of a training in selfregulation for students]," Zeitschrift für Pädagogische Psychologie, vol. 15, no. 3-4, pp. 181-197, 2001.

[68] M. Bannert, Metakognition beim Lernen mit Hypermedia. Erfassung, Beschreibung und Vermittlung Wirksamer Metakognitiver Strategien und Regulationsaktivitäten, . Waxmann, Münster, Germany, 2007.

[69] K. R. Hilden and M. Pressley, "Self-regulation through transactional strategies instruction," Reading and Writing Quarterly, vol. 23, no. 1, pp. 51-75, 2007.

[70] N. E. Perry, K. O. VandeKamp, L. K. Mercer, and C. J. Nordby, "Investigating teacher-student interactions that foster selfregulated learning," Educational Psychologist, vol. 37, no. 1, pp. 5-15, 2002.

[71] M. V. J. Veenman, "Alternative assessment of strategy use with self-report instruments: a discussion," Metacognition and Learning, vol. 6, no. 2, pp. 205-211, 2011.

[72] E. Hong and H. F. O'Neil, "Construct validation of a trait selfregulation model," International Journal of Psychology, vol. 36, no. 3, pp. 186-194, 2001.

[73] E. Hong, "A structural comparison between state and trait selfregulation models," Applied Cognitive Psychology, vol. 9, no. 4, pp. 333-349, 1995.

[74] E. Hong, "Differential stability of state and trait self-regulation in academic performance," The Journal of Educational Research, vol. 91, no. 3, pp. 148-158, 1998.

[75] B. Schmitz, M. Schmidt, M. Landmann, and C. Spiel, "New developments in the field of self-regulated learning," Journal of Psychology, vol. 215, no. 3, pp. 153-156, 2007.

[76] N. S. Endler, D. S. Crooks, and J. D. A. Parker, "The interactional model of anxiety: an empirical test in a parachute training situation," Anxiety, Stress, and Coping, vol. 5, pp. 301311, 1992.

[77] G. E. Hall, A. A. George, and W. L. Rutherford, Measuring Stages of Concern about the Innovation: A Manual for Use of the SoC Questionnaire, Research and Development Centre for Teacher Education. University of Texas, Austin, Tex, USA, 1977.

[78] N. Bitan-Friedlander, A. Dreyfus, and Z. Milgrom, "Types of "teachers in training": the reactions of primary school science teachers when confronted with the task of implementing an innovation," Teaching and Teacher Education, vol. 20, no. 6, pp. 607-619, 2004.

[79] D. H. Schunk and P.A. Ertmer, "Self-regulation and academic learning: self-efficacy enhancing interventions," in Handbook of Self-Regulation, M. Boekaerts, P. R. Pintrich, and M. Zeidner, Eds., pp. 631-651, Academic Press, San Diego, Calif, USA, 2000.
[80] M. Lüftenegger, B. Schober, R. van de Schoot, P. Wagner, M. Finsterwald, and C. Spiel, "Lifelong learning as a goal-do autonomy and self-regulation in school result in well prepared pupils?" Learning and Instruction, vol. 22, pp. 27-36, 2011. 


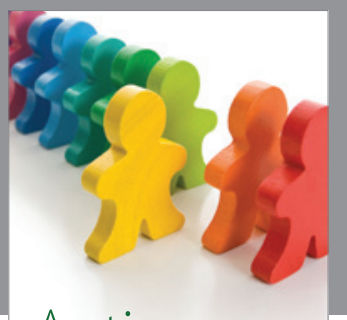

Autism

Research and Treatment
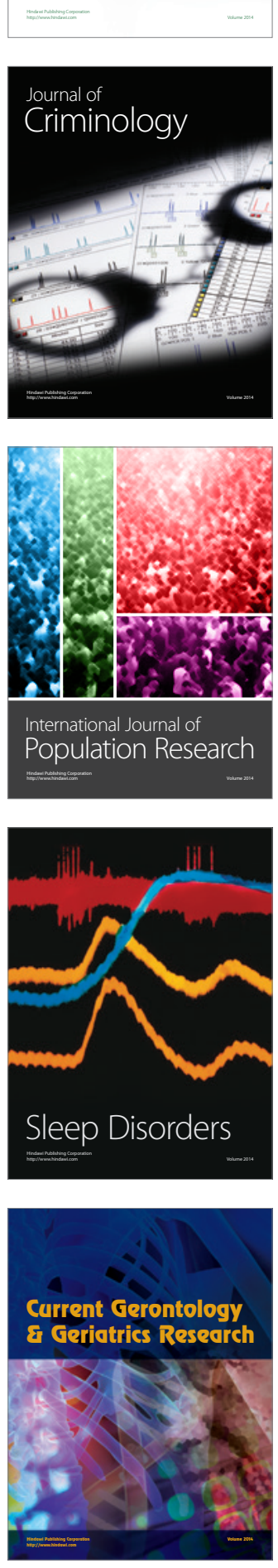
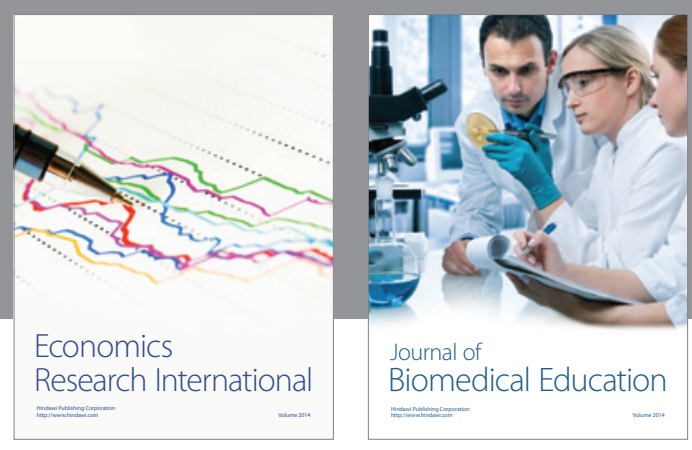

Journal of

Biomedical Education

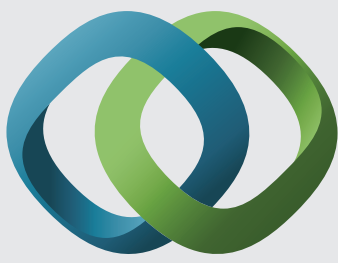

\section{Hindawi}

Submit your manuscripts at

http://www.hindawi.com
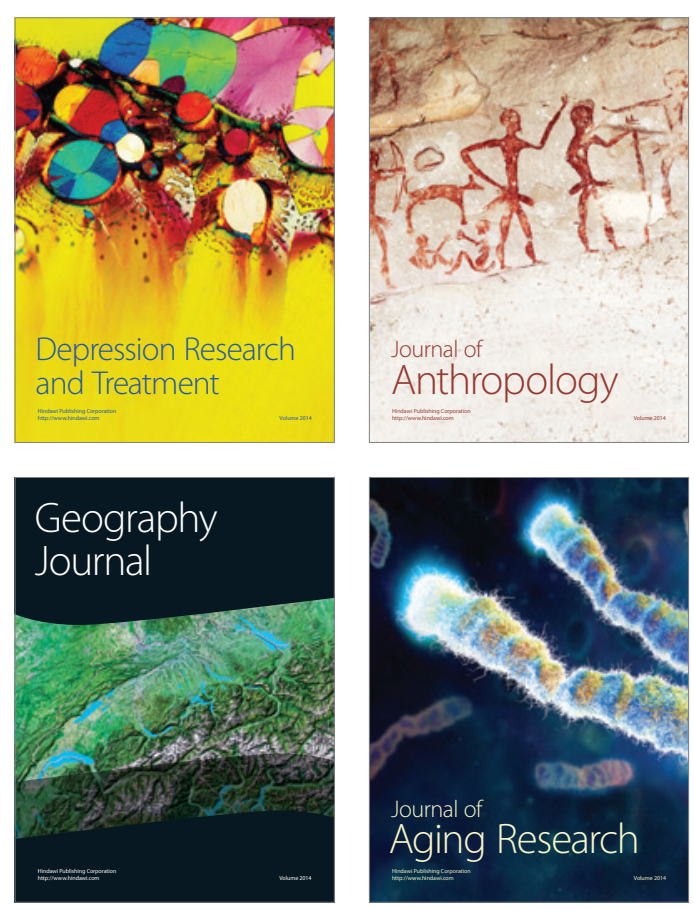

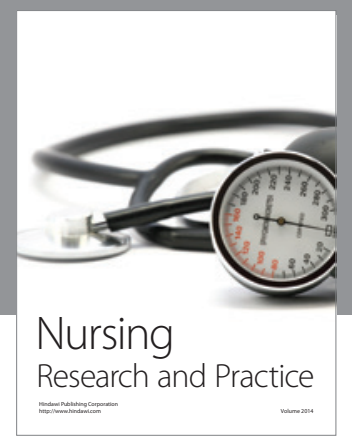

Nursing

Research and Practice

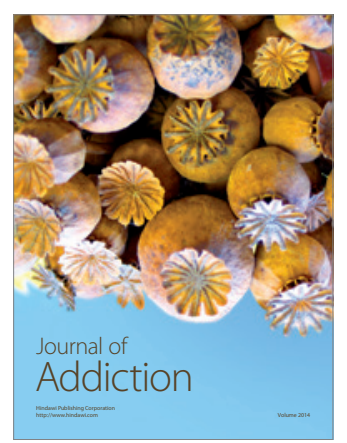

Child Development

Research

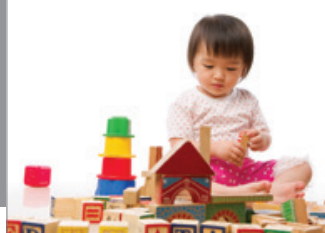

迥
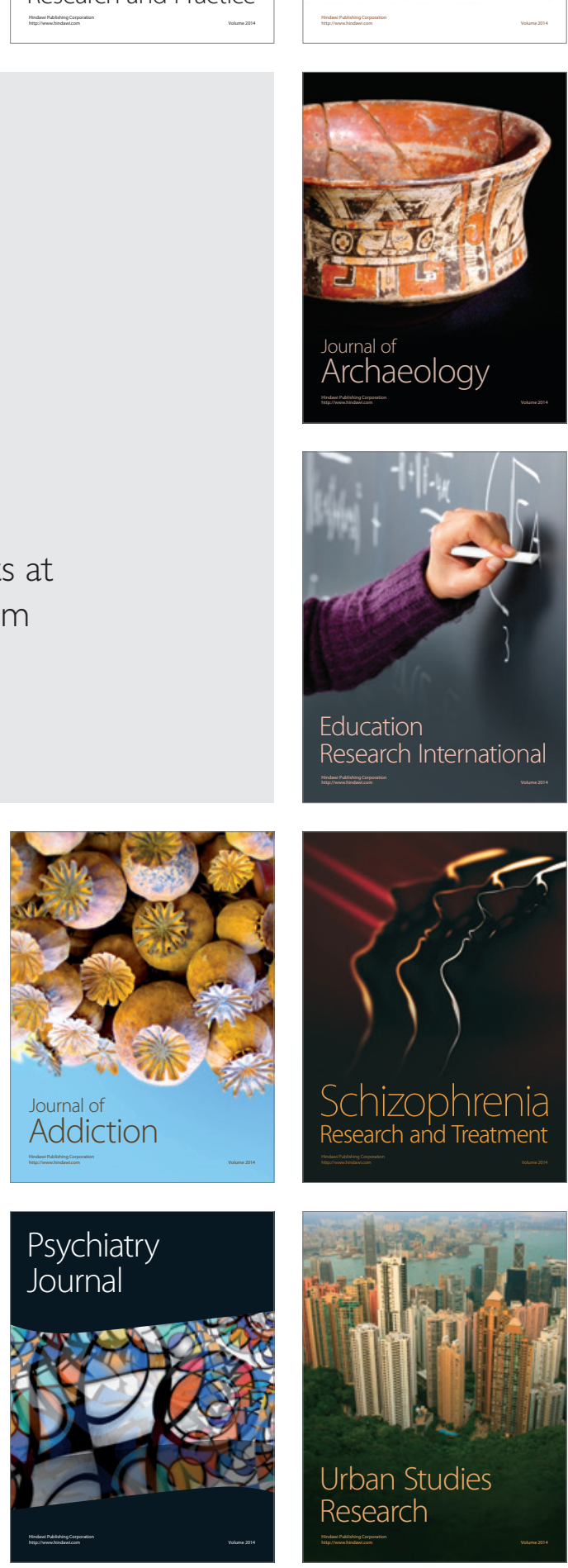